\title{
The foramen spinosum: a landmark in middle fossa surgery
}

\author{
Niklaus Krayenbühl • Gustavo Rassier Isolan • \\ Ossama Al-Mefty
}

Received: 21 September 2007 / Revised: 28 March 2008 / Accepted: 4 May 2008 / Published online: 2 August 2008

(C) Springer-Verlag 2008

\begin{abstract}
The foramen spinosum is an easily identifiable landmark in microsurgery of the middle cranial fossa, and knowledge of the variations in its relationship to the surrounding neurovascular structures is important when operating in this area. We studied the anatomical relationship of the foramen spinosum to the foramen ovale, the mandibular branch of the trigeminal nerve, the greater superficial petrosal nerve, and the petrous part of the internal carotid artery in 12 cadaver heads. We also tried to define an external landmark for early identification of the location of the foramen spinosum in ten dry skulls. We found considerable variations in the anatomy around the foramen spinosum. This knowledge may improve the identification and preservation of the neurovascular structures when using approaches to the middle cranial fossa.
\end{abstract}

Keywords Foramen spinosum · Middle fossa .

Greater petrosal nerve $\cdot$ Temporal bone $\cdot$ Anatomy

\section{Introduction}

The foramen spinosum (FS) was first described by the anatomist Jakob Benignus Winslow in the 18th century [8].

N. Krayenbühl · G. R. Isolan · O. Al-Mefty

Department of Neurosurgery,

University of Arkansas for Medical Sciences,

Little Rock, AR, USA

N. Krayenbühl $(\bowtie)$

Department of Neurosurgery, University Hospital Zürich,

Frauenklinikstrasse 10,

8091 Zürich, Switzerland

e-mail: nkrayenbuehl@bluewin.ch
Because of its close relationship to the small downwardprojecting spinous process of the greater wing of the sphenoid bone lying posteriorly to it, he called it the foramen spinosum. But the correct nomenclature should be foramen spinae, as "spinosum" means multiple thorns $[8$, 22]. Interestingly, the FS was not always confined to the sphenoid bone during the course of human evolution [3]. In earlier species, it is found in the squamous part of the temporal bone or on the sphenosquamosal suture, or it is absent [3]. It is therefore believed that during human evolution, the ossification of the posterior border of the greater wing of the sphenoid progressively developed around the middle meningeal artery [3].

Although the FS is an easily identifiable surgical landmark and has a close relationship to important neurovascular structures, its microsurgical anatomy has not been studied in detail. Neural structures like the trigeminal or greater superficial petrosal nerve may be distorted or invaded by tumor, making their identification during surgery difficult. An improved knowledge about the FS and its relationship to surrounding structures may help not only for middle fossa approaches, but also in trauma surgery when the foramen sometimes has to be explored in order to get proper hemostasis. In this study, we examined the relationship of the FS to the foramen ovale, the mandibular nerve $\left(\mathrm{V}_{3}\right)$, the greater superficial petrosal nerve (GSPN), and the petrous carotid artery, and tried to define a craniometric point to identify the location of the FS.

\section{Materials and methods}

The anatomy of the FS in relation to the surrounding structures was studied under $\times 3$ to $\times 40$ magnifications in 12 


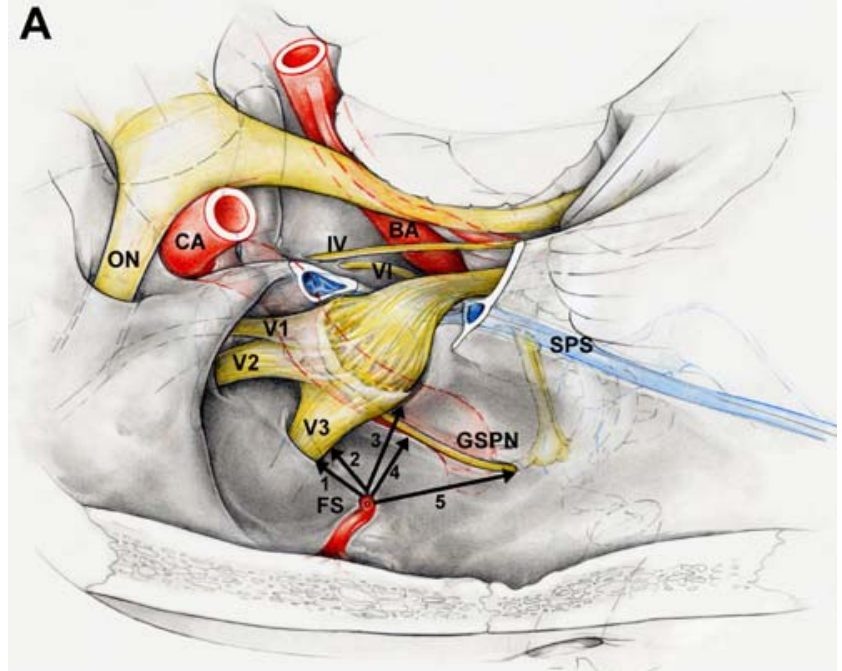

B

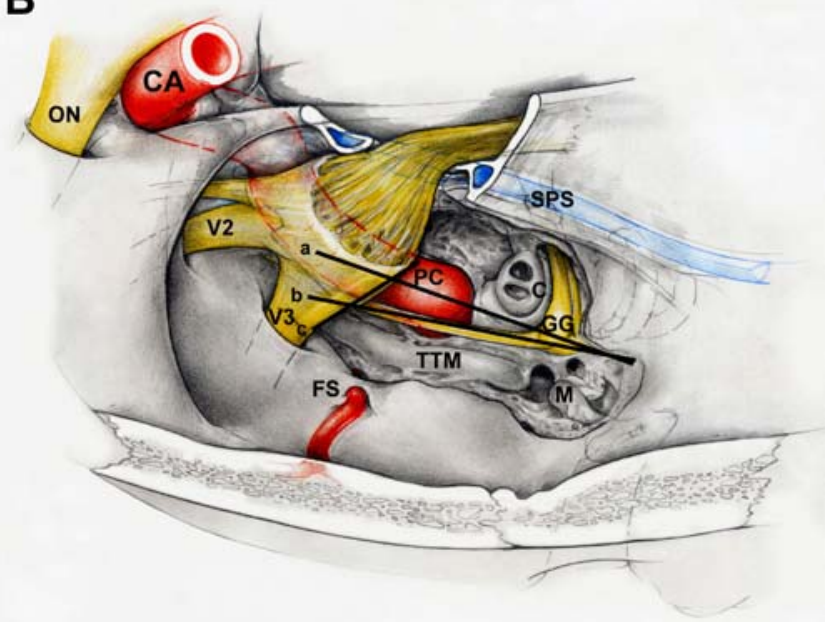

Fig. 1 Schematic illustration of Fig. 2 showing the measured distances and angles. A Distance measured from the foramen spinosum to: (1) the foramen ovale; (2) the mandibular branch of the trigeminal nerve $(V 3)$; (3) the middle of the petrous carotid artery $(P C)$; (4) the greater superficial petrosal nerve $(G S P N)$; (5) the entrance of the GSPN in the facial hiatus. $B A$ basilar artery, $C A$ carotid artery, $O N$ optic nerve, $S P S$ superior petrosal sinus, $I V$ trochlear nerve, $V 1, V 2, V 3$ branches of the trigeminal nerve, $V I$ abducens nerve. $\mathbf{B}$ Angles measured between the PC $(a)$ and the GSPN $(b)$ and the lateral border of V3 $(c)$. $c$ cochlea, $F S$ foramen spinosum, $G G$ geniculate ganglion, $M$ malleus, TTM tensor tympani muscle

formalin-fixed or fresh cadaver heads (24 sides). The arteries and veins were perfused with colored silicone. The dissection was done in a stepwise fashion from lateral to medial planes. The temporal dura propria was peeled from the middle fossa floor and the lateral wall of the cavernous sinus. The middle meningeal artery was cut at the exit of the FS and the dura further dissected from the roots of the trigeminal nerve and Meckel's Cave toward the petrous apex, taking care not to injure the GSPN. In the next step, the bone around the petrous carotid artery was drilled to expose its course along the entire length of the GSPN. The following measurements were then taken with a caliper: the diameter of the middle meningeal artery at its exit from the FS, and the distances from the middle of the FS to $V_{3}$, the GSPN, and the petrous carotid artery in $90^{\circ}$ angles. We also measured the distances to the closest border of the foramen ovale (FO) and to the entrance of the GSPN in the facial hiatus (Figs. 1 and 2). Digital photographs were then taken of all specimens at a view perpendicular to the middle fossa. The pictures were printed, and the angles between $\mathrm{V}_{3}$ and the GSPN and between the petrous carotid artery and GSPN were measured (Figs. 1 and 2).

To define an external landmark for the FS, ten dry skulls were examined ( 20 sides). The distance from the FS to the external margin of the zygomatic arch was measured along a line at a $90^{\circ}$ angle to the tabula interna of the squamous
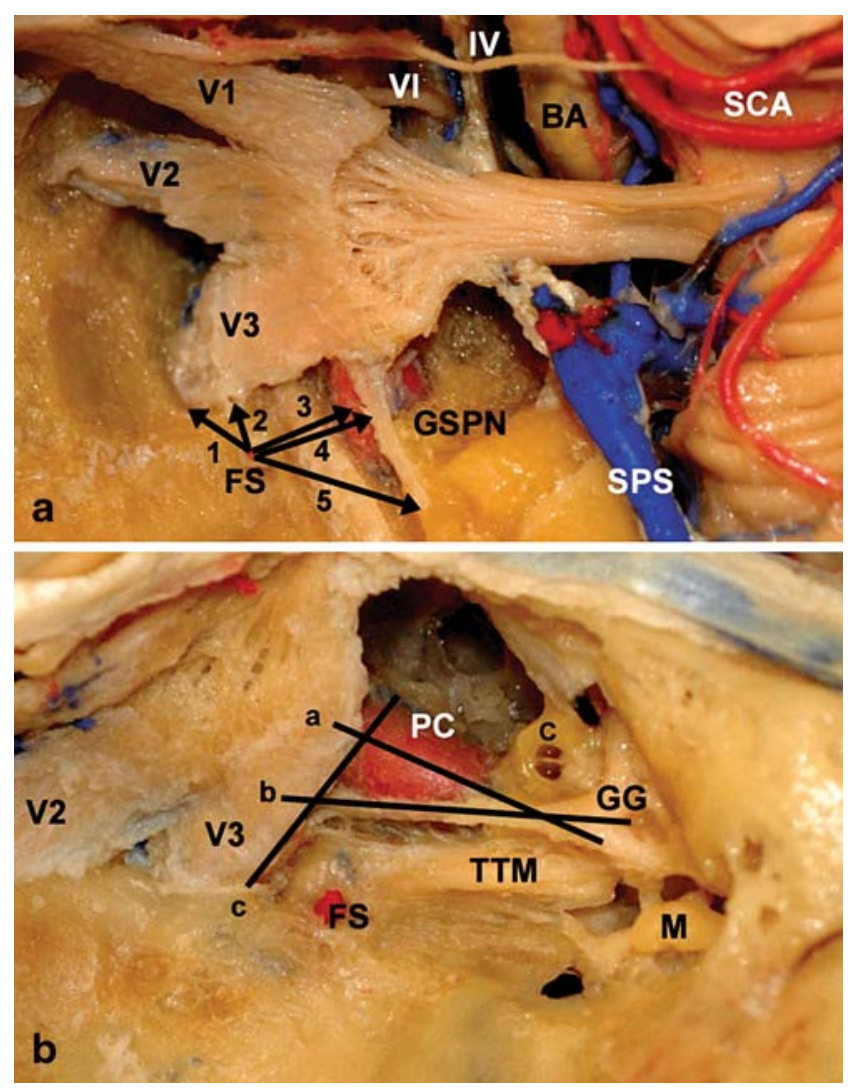

Fig. 2 A Distance measured from the foramen spinosum to: (1) the foramen ovale; (2) the mandibular branch of the trigeminal nerve (V3); (3) the middle of the petrous carotid artery $(P C)$; (4) the greater superficial petrosal nerve $(G S P N)$; (5) the entrance of the GSPN in the facial hiatus. $B A$ basilar artery, $C A$ carotid artery, $O N$ optic nerve, $S C A$ superior cerebellar artery, $S P S$ superior petrosal sinus, $I V$ trochlear nerve, $V 1, V 2, V 3$, branches of the trigeminal nerve, $V I$ abducens nerve. B Angles measured between the $P C(a)$ and the GSPN $(b)$ and the lateral border of $V 3(c) . c$ cochlea, $F S$ foramen spinosum, $G G$ geniculate ganglion, $M$ malleus, TTM tensor tympani muscle 

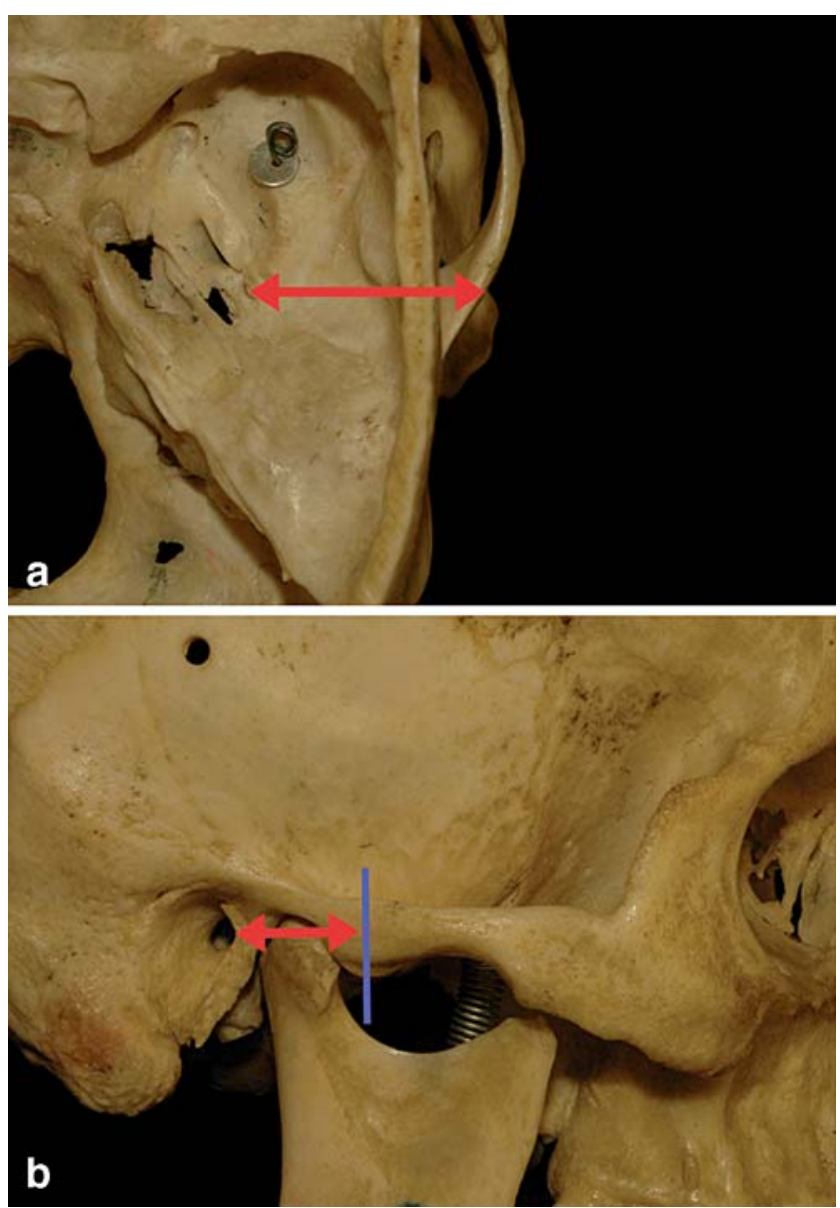

Fig. 3 A Distance measured between the foramen spinosum and the external margin of the zygomatic arch along a line perpendicular to the tabula interna of the squamous temporal bone. B Distance measured from the point of the external margin of the zygomatic arch obtained from Fig. 2a (blue line) and the anterior border of the external auditory meatus

temporal bone and from this point to the anterior border of the external auditory canal (Fig. 3).

\section{Results}

The following measurements were obtained: the diameter of the middle meningeal artery-median $1 \mathrm{~mm}$ (range 0.5 $2 \mathrm{~mm}$ ); the distance from the FS to the GSPN-median $7.75 \mathrm{~mm}$ (range $4.5-9 \mathrm{~mm}$ ); the distance from the FS to the petrous carotid artery-median $7.25 \mathrm{~mm}$ (range 5-11 mm); the distance from the FS to $\mathrm{V}_{3}$-median $4 \mathrm{~mm}$ (range 2$8 \mathrm{~mm}$ ); the distance from the FS to the FO-median $4.75 \mathrm{~mm}$ (range $2-7.5 \mathrm{~mm}$ ); and the distance from the FS to the facial hiatus-median $12 \mathrm{~mm}$ (range 9-17 mm). The median angle between the GSPN and $\mathrm{V}_{3}$ was $113^{\circ}$ (range $81-131^{\circ}$ ) and between the GSPN and the petrous carotid artery $7^{\circ}$ (range $0-179^{\circ}$; Table 1 ).
Table 1 Different distances measured in relation to the foramen spinosum

\begin{tabular}{lll}
\hline$N=24$ & Median (mm) & Range (mm) \\
\hline Diameter MMA & 1 & $0.5-2$ \\
Distance to GSPN & 7.75 & $4.5-9$ \\
Distance to PCA & 7.25 & $5-11$ \\
Distance to $\mathrm{V}_{3}$ & 4 & $2-8$ \\
Distance to FO & 4.75 & $2-7.5$ \\
Distance to FH & 12 & $9-17$ \\
& Median (degree) & Range (degree) \\
Angle GSPN and $\mathrm{V}_{3}$ & 113 & $81-131$ \\
Angle GSPN and PCA & 7 & $0-179$ \\
\hline
\end{tabular}

$M M$ middle meningeal artery, GSPN greater superficial petrosal nerve, $P C A$ petrous carotid artery, $V_{3}$ mandibular nerve, $F O$ foramen ovale, $\mathrm{FH}$ facial hiatus

Measurements taken on the dry skulls revealed the following distances: the FS to the lateral aspect of the zygomatic arch-median $28 \mathrm{~mm}$ (range $23-33 \mathrm{~mm}$ ), and the zygomatic arch to the external auditory meatus - mean $13 \mathrm{~mm}$ (range 10-21 mm; Table 2).

\section{Discussion}

The foramen spinosum (FS), through which passes the middle meningeal artery, the middle meningeal veins, which anastomose with the venous plexus of the foramen ovale or sinus cavernosus, and a recurrent branch of the mandibular nerve (nervus spinosus), is an important landmark for middle cranial fossa surgery. As mentioned, its name came from the spinous process of the greater wing of the sphenoid bone. This process, called the styliform process in the 18th century, has the anatomical term spina angularis sphenoidei, which is nowadays reduced to "spinous process" or "spine of the sphenoid" [24]. In humans, the size of the FS varies greatly, and one can find attached the sphenomandibular ligament, a remnant of the first branchial arch cartilage [9]. The FS may perforate the process at its apex or medial aspect, which is the reason the name canalis spinosus was also proposed [24]. However, the FS can also be located medial to the process. The FS is located antero-medially to the mandibular fossa,

Table 2 Distances measured for determination of an external landmark for the FS

\begin{tabular}{lcc}
\hline$N=20$ & Median (mm) & Range (mm) \\
\hline Distance to ZA & 28 & $23-33$ \\
Distance ZA to EAM & 13 & $10-21$ \\
\hline
\end{tabular}

$\mathrm{ZA}=$ Zygomatic arch

$\mathrm{EAM}=$ External auditory meatus 

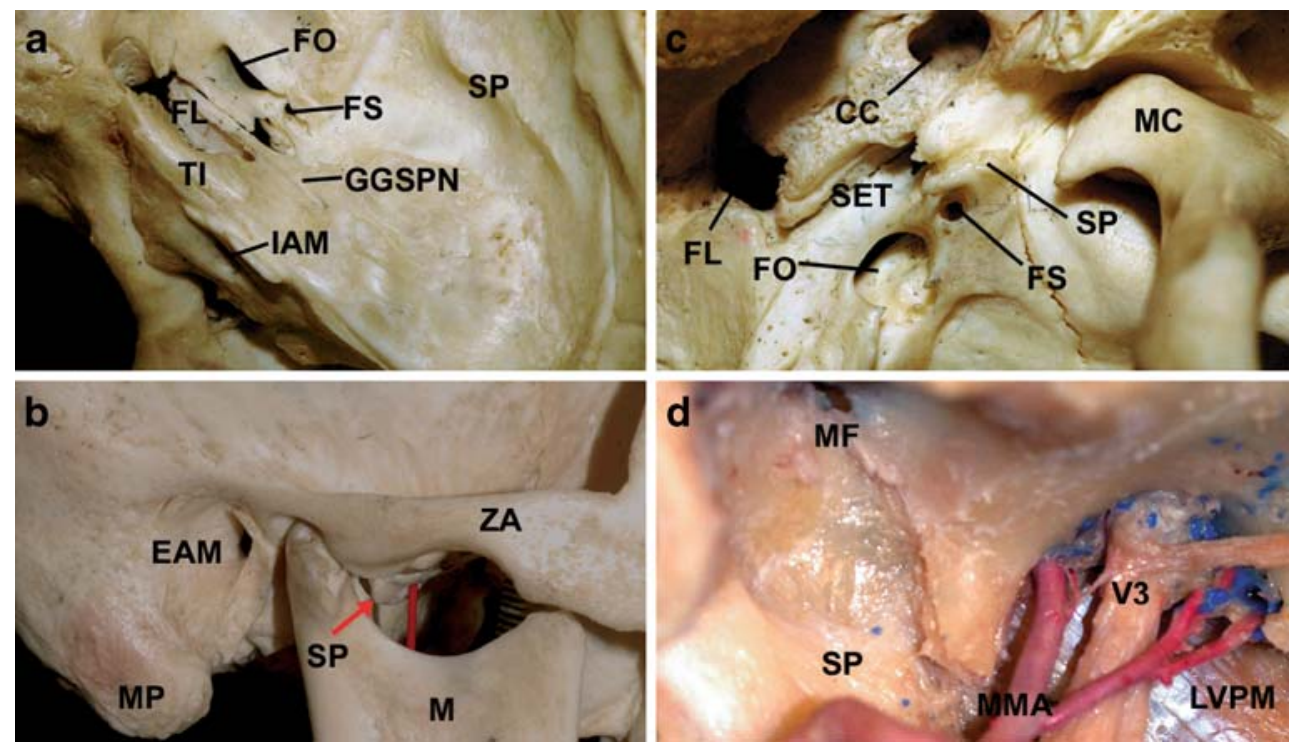

Fig. 4 A The superior aspect of the foramen spinosum. $F L$ foramen lacerum, $F O$ foramen ovale, $F S$ foramen spinosum, $G G S P N$ groove of greater superficial petrosal nerve, IAM internal acoustic meatus, $S P$ squamous part of the temporal bone, $T I$ trigeminal impression. B Lateral view showing the relationship with the zygomatic arch, the mandibula and the external auditory canal. Red rubber band: entry into the foramen spinosum. EAM external auditory meatus, $M$ mandibula, $M P$ mastoid process, $Z A$ zygomatic arch. $\mathbf{C}$ Inferior view

or postero-laterally to the FO [12] (Fig. 4). It is usually oval or round in shape and has a diameter of 1-4.3 $\mathrm{mm}$ (average $2 \mathrm{~mm}$ ) [1, 12, 13]. The rate of asymmetry of $>1.5 \mathrm{~mm}$ or $1 \mathrm{~mm}$ is $1 \%$ and $2 \%$, respectively $[1,13]$. It is unilaterally absent in $0.4-1 \%$ of cases $[1,2,10,13,16]$, rarely absent on both sides [21], and can be duplicated [6, 7, 13]. These variations may be important for the vascular supply of the dura as the middle meningeal artery in these cases may enter through the foramen ovale, or through the superior orbital fissure as a branch of the sphenomaxillary portion of the maxillary artery [14]. The middle meningeal artery can also arise from the ophthalmic artery, the lacrimal artery, or from the petrous (stapedial origin), cavernous, or supraclinoid portion of the internal carotid artery [14, 15, 16, 21]. Normally, the FS is separated from the foramen ovale, as we observed, but the distance can vary considerably. Incomplete separation occurs unilaterally in $1.6-2 \%$ and bilaterally in $1 \%$ of cases $[1,6,11]$. Incomplete formation of the FS is common [4, 6, 24]. Medial wall defects with communication with the sphenopetrosal fissure have been reported in up to $26.8 \%$ [6].

The eustachian tube, covered by bone, runs just posterior to the FS and parallel to the petrous carotid artery. Superior $(72 \%)$, anterior $(20 \%)$, and posterior $(8 \%)$ to the eustachian tube lies the tensor tympani muscle [5, 18]. As is the case with the geniculate ganglion or the petrous carotid artery, the tensor tympani muscle is not always covered by bone [1719, 20]. Variable ossification over the GSPN and geniculate of the foramen spinosum. $C C$ carotid canal, $F L$ foramen lacerum, $F O$ foramen ovale, $F S$ foramen spinosum, $M C$ mandibular condyle, $S E T$ sulcus of Eustachian tube, $S P$ spinous process. D Lateral view after removal of the temporomandibular joint, revealing the spinous process, and posterolateral to the entry of the middle meningeal artery in the foramen spinosum. $M F$ mandibular fossa, $M M A$ middle meningeal artery, LVPM levator veli palatini muscle, V3 mandibular nerve

ganglion may explain the difference in distance between the FS and the facial hiatus reported by others, who found a range of 6-13 $\mathrm{mm}$ [23]. Our range was 9-17 $\mathrm{mm}$. The GSPN runs parallel to the petrous carotid artery [18]. This was the case in only $21 \%$ of specimens in our series. In $46 \%$, the GSPN crossed the petrous carotid artery from medial to lateral directions. In relation to the FS, the GSPN was more lateral than the petrous carotid artery in $50 \%$ of specimens, at the same distance in $12.5 \%$, and more medial in $37.5 \%$. These variations should be kept in mind when the petrous carotid artery needs to be exposed during surgery. The angle of the GSPN with V3 also showed considerable variation.

We tried to define external landmarks for the FS but found a great variation in distances in relation to the anterior border of the external auditory meatus and the zygomatic arch. Lang measured the distance from the superior border of the zygomatic arch in the middle of the tuberculum articulare to the FS and found a mean distance of $31.5 \mathrm{~cm}$ (range 24 $39 \mathrm{~cm}$ ) in adults [12]. These external landmarks may help but cannot indicate the precise location of the FS.

\section{Conclusion}

Knowledge of the variations of anatomy around the foramen spinosum may help to better identify and preserve important neurovascular structures during approaches to the middle fossa. 
Acknowledgment Thanks to Mrs. R. Frick for helping with the references and to Mr. P. Roth for the illustrations.

\section{References}

1. Berge JK, Bergman RA (2001) Variations in size and in symmetry of foramina of the human skull. Clin Anat 14:406-413

2. Berlis A, Putz R, Schmuacher M (1992) Direct and CT measurements of canals and foramina of the skull base. Br J Radiol 65:653-661

3. Braga J, Crubezy E, Elyaqtine M (1998) The posterior border of the sphenoid greater wing and its phylogenetic usefulness in human evolution. Am J Phys Anthropol 107:387-399

4. Chopra R, Fergie N, Mehta D, Liew L (2003) The middle cranial fossa approach: an anatomical study. Surg Radiol Anat 24:348-351

5. De Oliveria E, Tedeschi H, Rhoton AL Jr, Peace DA (1995) Microsurgical anatomy of the internal carotid artery: intrapetrous, intracavernous, and clinoidal segments. In: Carter LP, Spetzler RF (eds) Neurovascular surgery. McGraw-Hill, New York, pp 3-10

6. Ginsberg LE, Pruett SW, Chen MY, Elster AD (1994) Skull-base foramina of the middle cranial fossa: reassessment of normal variation with high-resolution CT. Am J Neuroradiol 15:283-291

7. Gluncic V, Lukic IK, Ivkic G, Hat J, Marusic A (2002) Accessory foramen opticum, ovale, and spinosum. Case illustration. J Neurosurg 96:965

8. Goyanes JJB (1978) Onomatologia anatomica nova: Historia del lenguaje anatomico. Universidad de Valencia, Secretariado de Publicationes, Spain

9. Gray's anatomy, 39th edition (2005) Churchill Livingstone, New York, pp 461-467

10. Greig DM (1929) Congenital anomalies of the foramen spinosum. Edinb Med J 36:363-371

11. Keskil S, Gozil R, Calguner E (2003) Common surgical pitfalls in the skull. Surg Neurol 59:228-231

12. Lang J, Maier R, Schafhauser O (1984) Postnatal enlargement of the foramina rotundum, ovale and spinosum and their topographical changes. Anat Anz 156:351-387

13. Lindblom K (1936) A roentgenographic study of the vascular channels of the skull, with special reference to intracranial tumors and arteriovenous aneurysms. Acta Radiol Suppl (Stockholm) 30:1-146

14. Manjunath KY (2001) Anomalous origin of the middle meningeal artery-a review. J Anat Soc India 50:179-183

15. Martins C, Yasuda A, Campero A, Ulm AJ, Tanriover N, Rhoton A Jr (2005) Microsurgical anatomy of the dural arteries. Neurosurgery 56(2 Suppl):211-251

16. McLennan JE, Rosenbaum AE, Haughton VM (1974) Internal carotid origins of the middle meningeal artery. Neuroradiology 7:265-275

17. Pait TG, Harris FS, Paullus WS, Rhoton AL Jr (1977) Microsurgical anatomy and dissection of the temporal bone. Surg Neurol 8:363-391

18. Paullus WS, Pait TG, Rhoton AL Jr (1977) Microsurgical exposure of the petrous portion of the carotid artery. J Neurosurg 47:713-726

19. Rhoton AL Jr (2000) The temporal bone and transtemporal approaches. Neurosurgery 47(3 Suppl):S211-65

20. Rhoton AL Jr (1968) Absence of bone over the geniculate ganglion. J Neurosurg 28:48-53

21. Royle G, Motson R (1973) Anomalous origin of the middle meningeal artery. J Neurol Neurosurg Psychiatry 36:874-876

22. Triepel H, Stieve H (1943) Die anatomischen namen: ihre ableitung und Aussprache. Verlag von J. F. Bergmann, München, p 62
23. Tubbs RS, Custis JW, Salter EG, Sheetz J, Zehren SJ, Oakes WJ (2005) Landmarks for the greater petrosal nerve. Clin Anat $18: 210-214$

24. Wood-Jones F (1931) The non-metrical morphological characters of the skull as criteria for racial diagnosis. Part 1: General discussion of the morphological characters employed in racial diagnosis. J Anat 65:179-495

\section{Comments}

Alessandro Ducati, Torino, Italy

This paper begins with an erudite definition of the so-called "foramen spinosum" (FS); then it outlines the changes of FS during phylogenesis in human evolution, together with the posterior part of the sphenoid border. The main contribution is the report of the distances of FS from other structures of the middle fossa, namely, foramen ovale, V3, GSPN, intrapetrous carotid. I found this work particularly useful because the anatomy of middle fossa, with its variations, is the section of skull base surgery that is less familiar even to skull base surgeons. Approaches as frontoorbitozygomatic, or retrotranspetrosal, are more common and better known. Nevertheless, as the authors mention, knowing in detail the anatomy of middle cranial fossa may be critical even in simple traumatic cases (i.e., extradural haematomas), let alone meningiomas or vascular tumors of the temporal base or of the infratemporal space.

The review of the Literature is accurate, with excellent selection of recent papers, and goes back to the early 1940s, even to anatomical reports of the 1930s. The presentation of results is simple and essential, exactly what surgeons would like to read.

The only limitation of this valuable paper is, in my opinion, the lack of comparison between dissection measurements and neuroradiological data. I would have appreciated very much if the authors had given an idea of what, among these measurements, can be deduced from an accurate examination of skull base CT; or, better, if the CT measurements do correspond to anatomical findings obtained during dissection. Finally, "tips and tricks" to identify and dissect GSPN would have been helpful, since this is a structure that is both critical for orientation in middle fossa and difficult to identify at a glance during anatomical preparations or surgical procedures.

\section{Dattatraya Muzumdar, Mumbai, India}

The foramen spinosum is an important landmark in skull base surgery especially the middle fossa and infratemporal fossa. The middle meningeal artery is an important blood vessel, which can bleed furiously in a traumatic temporal extradural hemorrhage and also in vascular tumors involving the middle fossa base. Hence, understanding the different variations of foramen spinosum in terms of size, location, contents, and the temporal relationship to the surrounding critical neurovascular structures becomes paramount for the practicing skull base surgeon. There has been sparse literature on the subject, and more research on the subject is needed.

During human evolution, there is a clear trend for the foramen spinosum to be present and wholly located on the posterior area of the sphenoid greater wing. From ontogenetic studies in humans, the ossification of the posterior area of the sphenoid greater wing progressively surrounded the middle meningeal artery (passing through the foramen spinosum) and the small meningeal artery (passing through the foramen ovale). The middle meningeal artery is sometimes accompanied by a pair of dural sinuses throughout the majority of its course, which pass caudally through the foramen spinosum with the middle meningeal artery and diverge to form a plexiform arrangement around the artery. Variations of the intracranial venous sinuses are important to the surgeon during intraoperative procedures and to the clinician during imaging interpretation. The 
rarely reported accessory venous sinus of Hyrt is approximately $5 \mathrm{~mm}$ in width and travels from the sphenoparietal sinus anteriorly to the veins, draining into the foramen spinosum (i.e., the middle meningeal veins) posteriorly. The course of the lesser petrosal nerve has been shown in textbooks to be parallel to the greater petrosal nerve.

The use of modern imaging technology including CT and MR imaging is also helpful in identifying the anatomical variations of foramen spinosum in clinical practice. Image-guided surgery and the evaluation of ISG viewing wand for middle cranial fossa surgery has the potential advantage in accurate identification of important anatomic landmarks, even in the face of obscuring pathology.
Krayenbuhl et al. have studied the cadaveric anatomy in ten dry skulls. They conclude that there are considerable variations in the anatomy around the foramen spinosum and this in turn would improve identification and preservation of neurovascular structures around it. The authors have found marked variations in the distance around the foramen spinosum in ten dry skulls. There will be different variables according to population, race, gender, and genetic pool. Nevertheless, the authors have made a head start, and I would consider it as a pilot or a preliminary project and this should be studied in different regions of the world and include a significant sample size enough to make a powered study. 